\title{
Impact of delayed winter pruning on phenology and ripening kinetics of Pinot Noir grapevines
}

\author{
Matteo Gatti ${ }^{*}$, Tommaso Frioni, Alessandra Garavani, Arianna Biagioni, and Stefano Poni \\ Department of Sustainable Crop Production - DI.PRO.VE.S., Università Cattolica del Sacro Cuore, Via E. Parmense, 8429122 \\ Piacenza, Italy
}

\begin{abstract}
Climate change impacts viticulture with even stronger effects on sparkling wines. Innovative cultural practices represent effective short-term solutions. Among these, postponement of winter pruning later than budburst delayed both vegetative and reproductive cycles as well as technological maturity of several varieties from different wine regions. This research aims to assess the impact of delayed winter pruning on grapevine performance as a function of training system.

The trial was carried out in a Pinot Noir vineyard sited at $385 \mathrm{~m}$ asl in Central Italy. Delayed winter pruning was performed when unpruned canes had shoots showing three unfolded leaves (BBCH 13) and compared to standard winter pruning within two separate experiments focused on: i) cane pruning, and ii) spur pruning. Grapevine phenology, vegetative growth, fruit ripening kinetics and productivity of selected vines were assessed over three years. Delayed winter pruning postponed budburst by 20 and 31 days in Guyot and spur pruned cordons, respectively; then, differences diminished over time showing a maximum delay of 17 days at bloom and 7-10 days at harvest. Despite a decrease in yield (ranging from -35 to $-47 \%$ in cane and spur pruning, respectively), delayed winter pruning increased titratable acidity $(40-89 \%)$ and reduced sugars (7$21 \%$ ) as compared to control vines. Although effects of delayed pruning were stronger in spur pruned vines, delayed winter pruning was effective also on cane-pruned vines, therefore adapting to varieties marked by low basal-node fruitfulness.
\end{abstract}

\section{Introduction}

Climate is changing with direct impact on grapevine biology, especially as it concerns plant growth and fruit ripening. This variation in climatic trends is mainly related to increased air temperatures, higher $\mathrm{CO}_{2}$ in the atmosphere, and altered seasonal rainfall as observed in several wine districts. As a consequence, climate-change related issues can be summarized as faster sugar accumulation and depletion of organic acids in grapes, photo-oxidative degradation of phenolic compounds and alteration of aromatic profiles, all impacting wine balance and stability $[1,2]$. Despite new opportunities for emerging wine districts, this context threatens the quality of sparkling wines from traditional regions whose properties are strictly related to moderate alcohol concentration and appreciable acidity with specific regard to a sufficient malate concentration [3].

Several cultural practices for adapting viticulture to new climatic regimes have been reviewed by Palliotti et al. [2] and, among them, the postponement of winter pruning from dormancy to post-dormancy was proposed as a solution to delay grapevine phenology and ripening [4-9]. Based on the distinctive acrotony of Vitis vinifera, distal buds of unpruned canes develop first and exert growth inhibition on the subtending buds. As a consequence, a vegetative gradient sets along the cane and basal buds remain dormant [10]. If spur pruning is performed at this time, such physiological inhibition is removed and shoots from the basal nodes can start to develop. This second delayed budburst is obviously conducive to a consequent delay of both vegetative and reproductive cycles. Despite the fact that vines might compensate for the initial shift, the later winter pruning is performed, the higher the possibility to postpone the ripening process [4-6]. As a consequence, late winter pruning has the potential to either escape damages related to spring frost events or postponing the ripening process to a more suitable cooler period.

This work performed a three-year-assessment of effects of late winter pruning on phenology, plant growth, yield components, and fruit composition of Pinot Noir grapevines grown in Abruzzo (Central Italy) and intended for sparkling wine production. The paper also seeks to demonstrate whether spur or cane pruned vines have a differential response to the technique and if such a response is able to significantly alter the enological potential of the produced grapes.

\section{Material and Methods}

The trial included the following two experiments. 
Experiment 1.The trial was carried out over three years (2013-2015) in a five-year-old Pinot Noir block located in Ofena $\left(42^{\circ} 18^{\prime} \mathrm{N} 13^{\circ} 45^{\prime} \mathrm{E}\right.$, Central Italy, elevation of $385 \mathrm{~m}$ a.s.1.). Vines were $2.5 \mathrm{~m}$ and $0.8 \mathrm{~m}$ spaced between and within rows, respectively, corresponding to a plant density of 4,819 vines/ha. Rows were NS oriented and vines trained as VSP (Vertical Shoot Positioning) trellis with 10 nodes on the fruiting cane and 2 nodes on the spur. Three pairs of surmounting catch wires allowed a canopy wall extending $1.2 \mathrm{~m}$ above the fruiting cane.

Experiment 2. A two-year study (2014-2015) was performed in the same growing site already described as part of Exp1. Plant material, age, and spacing were equivalent. Vines were spur-pruned and trained to a VSP trellis for a resulting canopy wall extending $1.2 \mathrm{~m}$ above the setting wire. At pruning, six 2-node spurs were kept on the permanent cordon corresponding to a bud-load of 12 nodes per vine.

Both experiments used the same rootstock/scion combination (i.e. Pinot Noir, clone R4 grafted on 420A). In all trial years, vineyard and pest management were conducted according to the local protocols for sustainable viticulture. Mechanical shoot trimming was performed once per season when shoots outreached the top foliage wire by about $50 \mathrm{~cm}$.

A comparison between two pruning regimes (traditional winter pruning vs. late pruning) was performed in each of the two experiments. In detail, winter cane pruning (WCP) was compared to late cane pruning (LCP) as part of the experiment 1, whilst effects of late spur pruning (LSP) vs winter spur pruning (WSP) were assessed within experiment 2. With traditional winter pruning performed at dormancy, a pool of 63 vines for each of the two experiments was kept unpruned. Late pruning was performed on 30 April 2013, 2 May 2014 and 5 May 2015 when the shoots on node 10 of the unpruned canes had reached, on average, the stage of 3 unfolded leaves BBCH 13 [11].

Within each experiment, three adjacent rows were chosen to build a complete randomized block design with each row taken as a block. For each block, treatments were applied on a 3-bay space (corresponding to 21 vines) and four vine replicates were randomly chosen and tagged before bud-break, for subsequent detailed measurements.. Across consecutive seasons, treatments were applied on the same vines.

\section{Phenological trends}

Phenological stages were assessed after Lorenz et al. [11] in both Exp1 and Exp2 during the 2014 season. All twelve tagged vines per treatment were monitored twice a week from dormancy to onset of veraison and the $\mathrm{BBCH}$ stages of each shoot developed on every countnode from retained canes and/or spurs were recorded. Similarly, unfolded leaves were counted from bud-break to shoot trimming on the main shoot developed from each node position. Within every date, the median values for both unfolded leaves and $\mathrm{BBCH}$ readings identified along the different node positions were calculated and then averaged to describe seasonal variation of vegetative and reproductive cycles.

Ripening kinetics and harvest parameters.

Focused to the production of a traditional method sparkling wine, maturity was set at total soluble solids (TSS) concentration of about $20{ }^{\circ}$ Brix and titratable acidity (TA) not less than $7 \mathrm{~g} / \mathrm{L}$ in both WCP and WSP vines. In every experiment, berries were collected weekly from pre-veraison until approximately one month after harvest date in 2014 and 2015. For each treatment $x$ block combination, 100 healthy berries were randomly sampled from both the East and the West facing canopy side of the remaining 17 untagged vines. Grapes were immediately crushed and juice processed for determining TSS, TA and must $\mathrm{pH}$. Once ripening thresholds were met (3 September 2013, 1 September 2014 and 28 August 2015), all tagged vines were harvested, yield per vine weighed and bunch number per vine counted; accordingly, the average bunch weight was calculated.

At harvest, three bunches per vine were sampled and carried to the laboratory for subsequent chemical determinations. Mean berry weight was immediately calculated as based on a pool of 81 healthy berries randomly collected from the three bunches. A first subsample of 60 berries per vine was used to characterize fruit composition at harvest; fresh berries were pressed and the resulting juice used to determine TSS, TA and must $\mathrm{pH}$. In detail, total soluble solids were measured using a temperature-compensating RX 5000 refractometer (Atago-Co Ltd., Bellevue, WA, USA) and must $\mathrm{pH}$ determined with a digital PHM82 $\mathrm{pH}$-meter (Radiometer Analytical s.a.s., Villeurbanne Cedex, France). Titratable acidity was assessed by titration with $0.1 \mathrm{~N} \mathrm{NaOH}$ to a $\mathrm{pH} 8.2$ end-point and expressed as $\mathrm{g} / \mathrm{L}$ of tartrate equivalents. An additional aliquot of juice was used to quantify organic acids. Tartrate was assessed according to the colorimetric method based on silver nitrate and ammonium vanadate reactions[12]. Malate was determined by using an enzymatic kit (Megazyme International, Bray, Ireland). A second sub-sample of 60 berries per vine was frozen at $-20^{\circ} \mathrm{C}$ for subsequent determination of anthocyanins and phenolic compounds. Anthocyanin and total phenolic concentration was measured after Iland [13] and relative calculations were performed to express anthocyanins and phenolics as $\mathrm{mg} / \mathrm{g}$ of fresh weight.

Statistical analysis.

Within each experiment, data were processed by a twoway analysis of variance (ANOVA) using the IBM SPSS Statistics 24 software package. Treatment (T) and year (Y) were assumed as main factors of variation while interaction (TxY) was partitioned only when significant. Phenological trends and ripening curves were discussed by comparing mean values \pm standard error. 


\section{Results and Discussion}

Impact of late pruning on grapevine phenology and plant growth

Phenology of Pinot Noir grapevines was significantly affected by delayed winter pruning in 2014. Even if not compared within the same experiment, training system did not alter the seasonal canopy and fruit development in vines subjected to traditional long-cane (WCP) and spur (WSP) pruning (Fig. 1a and b). Progression of $\mathrm{BBCH}$ stages from dormancy to budburst was almost the same when vines were pruned at dormancy. Conversely, budburst was achieved 18 days later in LCP vines as compared to the WCP (Fig. 1a); bud swelling was consistently shifted over time by LSP and budburst postponed of 31 days respect to WSP (Fig. 1b). Although this effect is consistent with results achieved during former studies accomplished with different varieties, environmental and experimental conditions [49], the study brings innovative elements to the state-ofart on late winter pruning. As a matter of fact, our results demonstrate the effectiveness of this practice to postpone budburst in case of cane pruning (LCP), even though the magnitude of the phenological delay induced by LCP was lower as compared to LSP. This can be explained because in cane-pruned vines the final budload composition includes also median and distal nodes and a lower proportion of basal buds in which bud inhibition is much more intense.
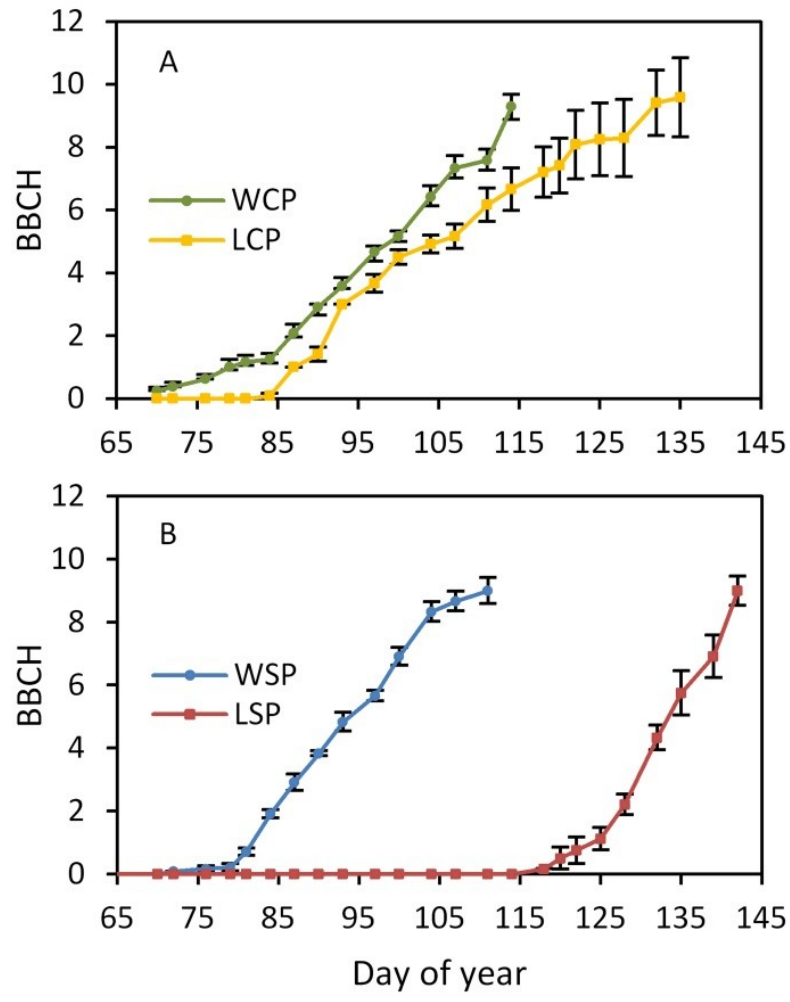

Fig. 1. Progression of $\mathrm{BBCH}$ stages from dormancy to budburst in cane (A) and spur (B) pruned Pinot Noir vines subjected to traditional winter pruning (WCP, WSP) and late pruning (LCP, LSP). Data 2014.

During shoot elongation, vegetative activity partially recovered the gap induced by late pruning. In particular, if the number of unfolded leaves on LSP was always lower than WSP, in Guyot-trained vines the delay on shoot growth steadily decreased until trimming when LCP offset the delay with WCP (data not shown).

Postponing winter pruning operations to spring resulted in effects on the reproductive cycle similar to those described for canopy development. Progression of $\mathrm{BBCH}$ stages from the stage at which inflorescences are clearly visible to full veraison are reported in figure 2 for both experiment 1 and 2 .
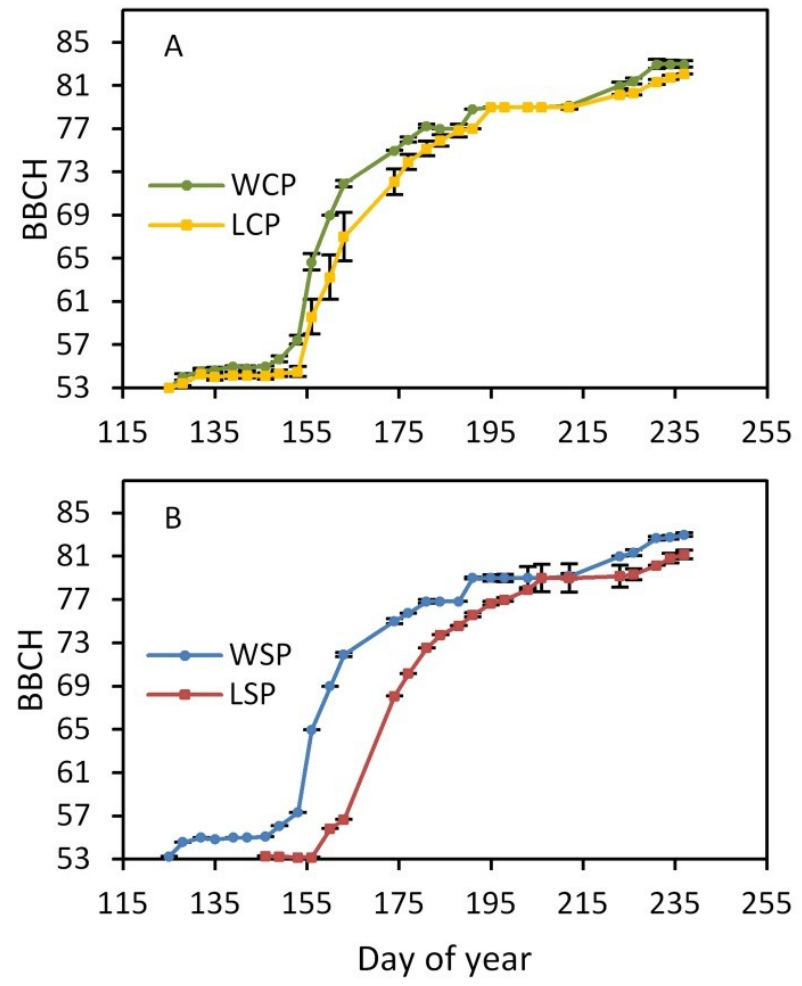

Fig. 2. Progression of $B B C H$ stages from inflorescences clearly visible to full veraison in cane (A) and spur (B) pruned Pinot Noir vines subjected to traditional winter pruning (WCP, WSP) and late pruning (LCP, LSP). Data 2014.

Clearly, late winter pruning, albeit with greater magnitude in LSP, also delayed bloom and veraison. In specific, full blooming (BBCH65) and onset of veraison (BBCH 81) in LCP vines occurred 7 and 8 days later than WCP (Fig. 2a), respectively, whilst the same developmental stages in LSP vines were shifted by 18 and 14 days as compared to WSP (Fig. 2b).

\section{Yield components and fruit composition}

WCP cropped an average of $1.42 \mathrm{~kg}$ of fruit corresponding to a tonnage of $6.84 \mathrm{t} / \mathrm{ha}$ (Tab. 1). Late pruning impacted on plant productivity by reducing vine yield by about $35 \%$ in LCP as compared to the winter pruned control (WCP). As a matter of fact, yield per vine was limited to $0.92 \mathrm{~kg} /$ vine when winter pruning was postponed to spring time. Such a decrease can be explained by considering the interaction among different yield components. Vines were similar in terms of bud number retained at pruning (12) and shoot number per canopy ( 9 and 10 in LCP and WCP, respectively); therefore, the lower yield per vine relates to the lower bunch number scored in LCP (12) against 18 bunches harvested in WCP. As a matter of fact, delayed winter 
pruning impacted shoot fruitfulness, which was significantly reduced from 1.61 (WCP) to 1.19 bunches/shoot when pruning operations were postponed after budburst. Moreover, LCP had also smaller berries ( $1.05 \mathrm{~g}$ in vs $1.22 \mathrm{~g}$ in WCP), whilst bunch weight was not affected by the two pruning regimes ( 76 and $79 \mathrm{~g}$ in LCP and WCP, respectively). As a result, bunch compactness was not different when pruning time was shifted from dormancy to spring time. The negative effect of late winter pruning on shoot fruitfulness has been already described by several authors that performed recent studies [4-9]. From a physiological perspective, the higher the leaf area removed with pruning, the higher the source limitation inducing reversion of already developed inflorescence primordia into tendrils [5]. It is also well known that gibberellins (GAs) produced by young leaves play an active role promoting floral inhibition [14].

Table 1. Total leaf area, vine balance and yield components of Guyot-trained Pinot Noir grapevines subjected to traditional winter pruning (WCP) and late pruning (LCP).

\begin{tabular}{|c|c|c|c|c|c|c|}
\hline & $\begin{array}{c}\text { LA } \\
\left(\mathrm{m}^{2} / \mathrm{vine}\right)\end{array}$ & $\begin{array}{c}\mathrm{LA} / \mathrm{Y} \\
\left(\mathrm{m}^{2} / \mathrm{kg}\right)\end{array}$ & $\begin{array}{c}\text { Yield } \\
(\mathrm{kg} / \mathrm{vin} \\
\mathrm{e})\end{array}$ & $\begin{array}{c}\text { Shoot } \\
\text { fruitful } \\
\text { ness }\end{array}$ & $\begin{array}{c}\text { Bunche } \\
\mathrm{s} / \text { vine }\end{array}$ & $\begin{array}{c}\text { Berry } \\
\mathrm{wt} \\
(\mathrm{g})\end{array}$ \\
\hline $\mathrm{WCP}$ & $3.48 \mathrm{a}$ & $3.00 \mathrm{~b}$ & $1.42 \mathrm{a}$ & $1.61 \mathrm{a}$ & $18 \mathrm{a}$ & $1.22 \mathrm{a}$ \\
\hline $\mathrm{LCP}$ & $3.06 \mathrm{~b}$ & $4.74 \mathrm{a}$ & $0.92 \mathrm{~b}$ & $1.19 \mathrm{~b}$ & $12 \mathrm{~b}$ & $1.05 \mathrm{~b}$ \\
\hline $\mathrm{Sig}$. & $* *$ & $* * *$ & $* * *$ & $* *$ & $* * *$ & $* * *$ \\
\hline
\end{tabular}

Table 2. Fruit composition of Guyot-trained Pinot Noir grapevines subjected to traditional winter pruning (WCP) and late pruning (LCP).

\begin{tabular}{|c|c|c|c|c|c|c|}
\hline & $\begin{array}{c}\text { TSS } \\
(\text { Brix })\end{array}$ & $\begin{array}{c}\text { TA } \\
(\mathrm{g} / \mathrm{L})\end{array}$ & $\mathrm{pH}$ & $\begin{array}{c}\text { Malate } \\
(\mathrm{g} / \mathrm{L})\end{array}$ & $\begin{array}{c}\text { Tartrate } \\
(\mathrm{g} / \mathrm{L})\end{array}$ & $\begin{array}{c}\text { Anthocy } \\
\text { anins } \\
(\mathrm{mg} / \mathrm{g})\end{array}$ \\
\hline $\mathrm{WCP}$ & $21.3 \mathrm{a}$ & $7.2 \mathrm{~b}$ & $3.32 \mathrm{a}$ & $2.44 \mathrm{~b}$ & $5.91 \mathrm{~b}$ & 0.629 \\
\hline $\mathrm{LCP}$ & $19.7 \mathrm{~b}$ & $10.1 \mathrm{a}$ & $3.13 \mathrm{~b}$ & $4.01 \mathrm{a}$ & $6.43 \mathrm{a}$ & 0.657 \\
\hline Sig. & $* * *$ & $* * *$ & $* * *$ & $* * *$ & $* *$ & $\mathrm{~ns}$ \\
\hline
\end{tabular}

Comparing the magnitude of late pruning's impact on productivity of vines subjected to different pruning regimes, it is quite evident that cane pruning induced a moderate yield contraction (-35\%) with respect to spur pruning $(-47 \%)$ (Tab. 3).This fact can be explained because in cane-pruned vines, the bud load composition includes also median and distal nodes and a lower proportion of basal buds in which floral inhibition is much greater. Accordingly, late pruning lowered shoot fruitfulness by $48 \%$ and $27 \%$ in spur pruning and cane pruning, respectively (Tab. 3).

Late pruning shifted the ripening process in both the pruning systems (Fig.3). Ripening curves for TSS and TA were successfully delayed by LCP and LSP as compared to the respective controls. In 2014, sugar accumulation was postponed by 6 and 10 days by LCP and LSP, respectively. Similarly, TA decrease was delayed more markedly in LSP than in LCP. After harvest, both the treatments (LCP, LSP) had higher acidity than their controls (WCP, WSP).

Late pruning altered fruit composition at harvest by reducing sugars and retaining higher acidity as compared to control vines (Tab.2). With $19.7^{\circ} \mathrm{Brix}$, LCP reduced TSS by $1.6{ }^{\circ}$ Brix when compared to WCP, corresponding to a $7 \%$ decrease. Must $\mathrm{pH}$ was significantly lower in LCP as compared to traditional winter pruning. In parallel, LCP had higher TA than control $(10.1$ vs $7.2 \mathrm{~g} / \mathrm{L})$ also as reflected by the concentration of individual organic acids. Based on common indicators of technological maturity, late pruning affected not only their concentrations but also their proportion. Specifically, the malate-to-tartrate ratio increased from 0.41 in WCP to 0.62 in LCP making this practice particularly attractive for growers in the sparkling-wine industry. Contrariwise, late pruning did not change anthocyanin concentrations in grapes, suggesting that comparing treatments when picked at similar technological maturity (comparable TSS in juice), LCP might show a higher colour rate as compared to WCP. This condition should be supported by the different vine balance induced by late pruning through the lower crop load and the improved leaf-to-fruit ratio (Tab. 1).

Table 3. Impact of late pruning on agronomical and enological variables of Pinot Noir grapevines as a function of pruning system. Values corresponding to percent variation of late pruning vs respective traditional cane and spur winter pruning.

\begin{tabular}{|c|c|c|}
\hline Variable & $\begin{array}{c}\text { Cane pruning } \\
\text { (Exp. 1) }\end{array}$ & $\begin{array}{c}\text { Spur pruning } \\
\text { (Exp. 2) }\end{array}$ \\
\hline Shoots/vine & -9.1 & -3.5 \\
\hline Total LA & -12.1 & -4.1 \\
\hline LA/Y & +58 & +81.2 \\
\hline Yield & -35.2 & -47.1 \\
\hline $\begin{array}{c}\text { Shoot } \\
\text { fruitfulness }\end{array}$ & -26.7 & -48.2 \\
\hline Berry wt. & -13.9 & -10.7 \\
\hline TSS & -7.5 & -20.8 \\
\hline TA & +40.3 & +89.5 \\
\hline pH & -5.7 & -11.6 \\
\hline Malate & +64.3 & +163.7 \\
\hline
\end{tabular}




\begin{tabular}{|l|l|l|}
\hline Tartrate & +8.8 & +17.1 \\
\hline
\end{tabular}

As already presented for yield components, the intensity of late pruning effects on fruit composition was greater in the case of spur pruning. Accordingly, TSS was reduced by $7.5 \%$ and $21 \%$ in cane and spur pruning, respectively, whilst TA was $40 \%$ and $89 \%$ higher than traditional pruning (Tab. 3). However, when winter pruning was postponed, both pruning systems shared the highest impact on malate concentration that was associated to the following variation rates: $+64 \%$ and $+164 \%$ in cane and spur pruning, respectively (Tab. 3 ).
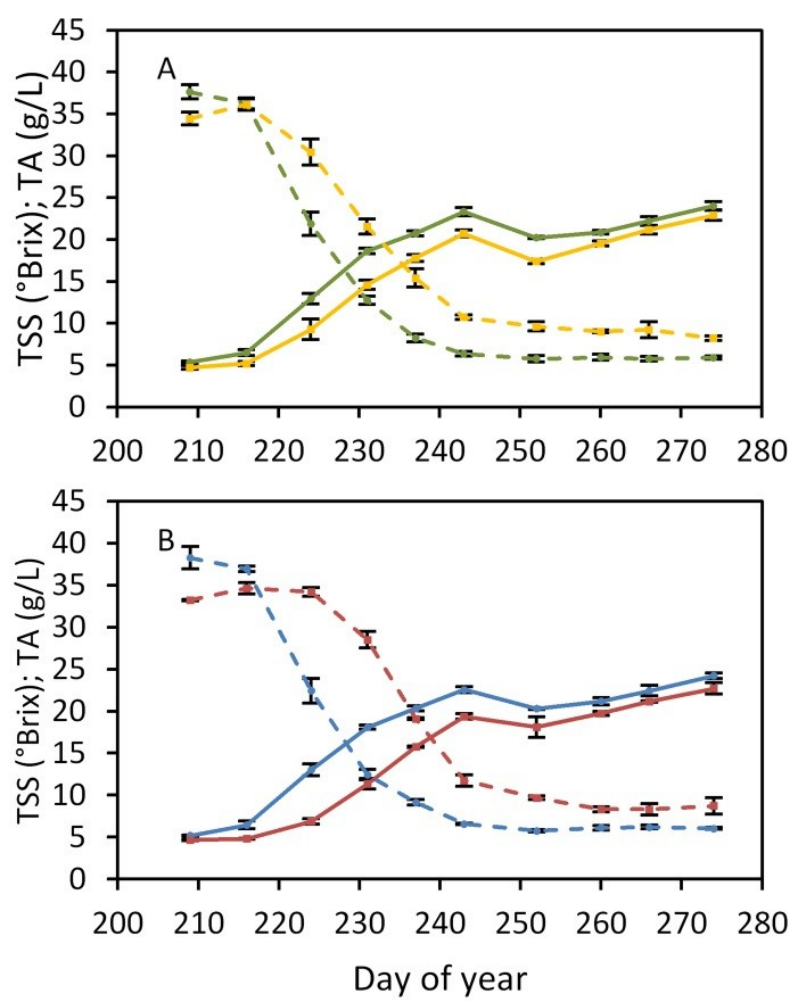

Fig. 3. Variation of must TSS (solid lines) and TA (dotted lines) in cane (A) and spur (B) pruned Pinot Noir vines subjected to traditional winter pruning (WCP in green, WSP in blue) and late pruning (LCP in yellow, LSP in red). Data 2014.

\section{Conclusions}

Late pruning delayed phenology, and changed fruit composition of Pinot Noir grapevines subjected to different pruning regimes (cane and spur pruning). As expected, the greater impact is associated to spur pruning. The main limitation of late pruning is the negative impact of shoot fruitfulness and yield. This research points out how late pruning can be successfully applied also on cane pruned vines, even though further studies are required to clarify within-cane variability of shoot growth, yield and fruit composition. Targeting the production of sparkling wines, this practice can successfully postpone technological maturity slowing down the loss of acidity. Facing the climate-change related issues late pruning not only preserves the TSS/TA balance over time but also is effective in altering the proportions of organic acids in favor of malate. Based on our results, late pruning is a promising technique in either spur- or cane-pruned vineyards, representing a feasible solution also for varieties featured by low basal-bud fruitfulness and precocity.

This project was funded by Azienda Marramiero S.r.l., Rosciano (Italy). The authors thank the vineyard crew at the winery for skilled technical assistance and support with field scouting.

\section{References}

1. G.V. Jones, M.A. White, O.R. Cooper, K. Storchmann, Clim. Change 73, 319-343 (2005).

2. A. Palliotti, S. Tombesi, O. Silvestroni, V. Lanari, M. Gatti, S. Poni, Sci. Hortic.178, 43-54 (2014).

3. S. Poni, M. Gatti, A. Palliotti, Z.W. Dai, E. Duchêne, T.T. Truong, G. Ferrara, A.M.S. Matarrese, A. Gallotta, A. Bellincontro, F. Mencarelli, S. Tombesi, Sci. Hortic. 234, 445-462 (2018).

4. T. Frioni, S. Tombesi, O. Silvestroni, V. Lanari, A. Bellincontro, P. Sabbatini, M. Gatti, S. Poni, A. Palliotti, Am. J.Enol. Vitic. 67, 419-425 (2016).

5. M. Gatti, F.J. Pirez, G. Chiari, S. Tombesi, A. Palliotti, M.C. Merli, S. Poni, Front. Plant Sci. 7, 659 (2016).

6. A. Palliotti, T. Frioni, S. Tombesi, P. Sabbatini, J.G. Cruz-Castillo, V. Lanari, O. Silvestroni, M. Gatti, S. Poni, Am. J.Enol. Vitic. 68, 412-421 (2017).

7. M.A. Moran, V.O. Sadras, P.R. Petrie, Aust. J. Grape Wine Res. 23, 390-398 (2017).

8. P.R. Petrie, S.J. Brooke, M.A. Moran, V.O. Sadras, Aust. J. Grape Wine Res. 23, 378-389 (2017).

9. W. Zheng, J. García, P. Balda, F.M. De Toda, J. Int. Sci. Vigne Vin 51, 363-372 (2017).

10. A.P. Friend, M.C. Trought, Aust. J. Grape Wine Res. 13, 157-164 (2007).

11. D.H. Lorenz, K.W. Eichhorn, H. Bleiholder, R. Klose, U. Meier, E. Weber, Aust. J. Grape Wine Res. 1, 100-103 (1995).

12. Z. Lipka, H. Tanner, Revue Suisse d'Agriculture, de Viticulture et d'Arboriculture 6, 5-10 (1974).

13. P.G. Iland, Proc. $2^{\text {nd }}$ Int. Cool Clim. Vitic. And Oenol.Symp., 137-138 (1988).

14. C. Srinivasan, M.G. Mullins, Am. J. Enol. Vitic. 32,47-63 (1981). 